\title{
Claus Arnold, Giacomo Losito, « Lamentabili sane exitu » (1907). Les documents préparatoires du Saint-Office
}

Rome, Libreria Editrice Vaticana, 2011, 546 p.

Jean-Louis Schlegel

\section{OpenEdition \\ Journals}

\section{Édition électronique}

URL : http://journals.openedition.org/assr/25163

DOI : $10.4000 /$ assr.25163

ISSN : $1777-5825$

\section{Éditeur}

Éditions de l'EHESS

Édition imprimée

Date de publication : 30 décembre 2013

Pagination : 129

ISSN : 0335-5985

Référence électronique

Jean-Louis Schlegel, « Claus Arnold, Giacomo Losito, «Lamentabili sane exitu » (1907). Les documents préparatoires du Saint-Office», Archives de sciences sociales des religions [En ligne], 164 2013, mis en ligne le 14 février 2014, consulté le 21 septembre 2020. URL : http:// journals.openedition.org/assr/25163; DOI : https://doi.org/10.4000/assr.25163

Ce document a été généré automatiquement le 21 septembre 2020.

(c) Archives de sciences sociales des religions 
Claus Arnold, Giacomo Losito, «Lamentabili sane exitu » (1907). Les documents préparatoires du Saint-Office

Rome, Libreria Editrice Vaticana, 2011, 546 p.

Jean-Louis Schlegel

RÉFÉRENCE

Claus Arnold, Giacomo Losito, «Lamentabili sane exitu » (1907). Les documents préparatoires du Saint-Office, Rome, Libreria Editrice Vaticana, 2011, 546 p. 
Le 8 juillet 1907, le Saint-Office condamne, par le décret Lamentabili sane exitu, 65 propositions tirées des œuvres d'Alfred Loisy (rappelons que cette même année, en septembre, ce dernier sera frappé par une autre condamnation: celle de l'encyclique Pascendi, du pape Pie X, «sur les erreurs du modernisme »). Grâce à l'ouverture des Archives de la Congrégation pour la Doctrine de la Foi en 1998 (archives en cours d'édition et de publication), C. Arnold et G. Losito ont eu accès aux documents préparatoires du décret, qui s'étendent de 1903 à 1907. L'écart de quatre ans entre la mise à l'index et la publication de Lamentabili trahit le côté laborieux de l'élaboration du texte final. Ce n'est pas l'intransigeance globale contre Loisy qui est en cause, mais


au sein du camp intransigeant il y a plus que des nuances sur le genre et le contenu du document à réaliser - sans compter des hostilités personnelles pour des raisons diverses. Les deux consulteurs que les cardinaux du Saint-Office chargent de rédiger l'elenchus errorum (examen des erreurs) de Loisy lui sont très hostiles, pour des raisons différentes : Domenico Palmieri, un jésuite, est soucieux de plaire à Pie $\mathrm{X}$, après avoir éprouvé quelques difficultés avec Léon XIII ; les convictions de Pie de Langogne, un capucin, rejoignent celles des milieux français les plus intransigeants, souvent en train de devenir maurrassiens. En 1904, Palmieri et Langogne présentent chacun leur liste de propositions à condamner: 93 pour Palmieri, qui les extrait des œuvres de Loisy et les qualifie pour la plupart d'« hérétiques »; 119 pour Langogne, qui puise ses formulations dans les critiques et les dénonciations des adversaires français de Loisy et aussi d'autres "novateurs" (en particulier Mgr Mignot, archevêque d'Albi) ; en fait, il fait feu de tout bois pour accabler Loisy et les modernistes, sans être totalement fermé à leurs recherches. On demande cependant aux deux rapporteurs de réunir leurs contributions en un seul document, et ils parviennent ainsi, avec l'aide d'un troisième consulteur, Willem van Rossum, à 93 propositions, où dominent celles de Pie de Langogne. Il faudra trois ans ensuite, et diverses péripéties, pour parvenir au texte final, où il en restera 65 (ce qui montre malgré tout l'élimination d'un nombre important de propositions à condamner, d'autres étant nettement atténuées). Il a été décidé dès 1904 que le document à élaborer devra se cantonner aux écrits de Loisy et à la France, sans déborder sur le modernisme en général - l'encyclique Pascendi s'en chargera, on l'a dit, trois mois après. Cela veut dire qu'on en restera aux questions posées par l'exégèse historique de Loisy. En 1905, après un certain nombre de séances de discussion, les consulteurs arrivent à un premier accord, soumis à l'assemblée des cardinaux du Saint-Office. Ces derniers le retournent ensuite avec leurs remarques aux consulteurs, qui le retravaillent encore pour arriver à la réécriture finale, approuvée par les cardinaux et le pape en juin 1907. Les propositions condamnées ne sont pas «qualifiées » (d'hérésie, par exemple), ce qui laissera une latitude pour en interpréter la portée. C'était aussi une décision de 
prudence, car la qualification d'hérésie aurait impliqué qu'on soit certain du dogme à propos de diverses questions - ce qui n'était pas le cas. Cependant, de 1904 à 1907, donc en même temps qu'on peaufine le décret, Loisy reste un sujet de préoccupation et d'irritation, en particulier à propos de son esprit d'obéissance et surtout de soumission. Il continue de faire cours à l'École des hautes études, où des intransigeants se mêlent au public pour surveiller ses propos et... identifier ceux qui viennent l'écouter. Les correspondances à son sujet vont bon train. Malgré tout, Arnold et Losito soulignent que Lamentabili sane exitu va globalement dans le sens d'une atténuation des accusations intransigeantes du début, et même d'une certaine ouverture à la réflexion sur les rapports entre histoire et dogme. Tous les consulteurs et tous les cardinaux ne sont pas insensibles aux nouvelles questions posées par l'exégèse critique. Ils semblent connaître, par exemple, l'évolution historique du Credo, ou encore ils s'interrogent sur le rôle de la raison humaine dans la connaissance des vérités de foi. De plus, l'un des adversaires les plus fermes de Palmieri et Langogne est le cardinal Lepidi, maître du Sacré-Palais, et il n'est pas le seul personnage de haut rang ouvert à la «nouveauté ». En fin de compte, si l'exégèse catholique restera verrouillée pendant quarante ans, jusqu'à la publication de Divino afflante Spiritu, c'est bien plus à cause de Pascendi, l'encyclique pontificale, qu'en raison de Lamentabili, le décret du Saint-Office. Comme on le sait, malgré les pressions intenses, faisant appel à toutes les ressources qu'un chantage ecclésiastique peut inventer, Loisy refusera de se soumettre et, en 1908, il sera excommunié vitandus: tout contact avec lui est interdit (sauf aide matérielle ou spirituelle de nécessité). Du côté des commentaires, français ou non, beaucoup applaudissent, mais plus d'un s'évertue à dire que ce n'est pas un nouveau "syllabus » et que l'Église ne condamne pas la science, mais uniquement des dérapages dangereux.

2 Toutes les informations qui précèdent viennent des textes d'introduction par les deux éditeurs, Claus Arnold et Giacomo Losito. Dans l'avant-propos, avec un «cadrage historique des études modernistes ", Émile Poulat contextualise le décret en soulignant ce qu'il en était des rapports entre histoire et foi au début $d u x^{e}$ siècle, sans oublier de remarquer que le "régime de séparation" entre les deux domaines est devenu aujourd'hui irrémédiable (et donc que les commentaires minimisant le fossé entre science historique et foi n'étaient pas pertinents). Il loue aussi à bon droit le travail des deux éditeurs, tout en notant qu'il eût été intéressant de comparer aujourd'hui le texte des propositions condamnées et ce que Loisy a effectivement écrit. À juste titre, Poulat souligne aussi qu'on attend désormais les documents préparatoires à l'encyclique Pascendi. N'oublions pas, en effet, que le corps de l'ouvrage est constitué des documents préparatoires du Saint-Office (en latin, sauf les textes cités de Loisy et d'autres auteurs français, ainsi que les notes en français des éditeurs) tirés des archives de la Congrégation pour la Doctrine de la Foi (propositions de Palmieri et Langogne, réactions des consulteurs et des cardinaux, rédaction des documents successifs). Le lecteur intéressé - et latiniste - y trouvera maintes informations inédites.

3 Cependant, si ingrat qu'en soit l'aveu, un regret ou une réserve d'importance doivent être faits : pour des raisons qu'il n'y a pas lieu de critiquer, le français écrit des deux éditeurs est très approximatif; or leurs textes sont ici publiés tels quels, avec de nombreuses incorrections, sans qu'un relecteur n'ait procédé aux corrections nécessaires. Pour le texte d'Arnold, déjà publié ailleurs, les Éditions vaticanes ont même gardé les corrections barrées qu'il a pu réaliser sur la première version. Ce n'était pourtant pas un immense travail que de remettre le tout en bon français et d'enlever 
les phrases barrées. Conséquence de la misère ou de la négligence ? Ce n'est pas une catastrophe - car les textes sont très lisibles -, mais surprenant et désolant pour un travail si savant et minutieux par ailleurs. 